\title{
A Gestão do Conhecimento no processo virtual de desenvolvimento de produtos
}

\author{
Ricardo M. Naveiro, D.Sc. \\ Escola Politécnica da UFRJ e COPPE/UFRJ \\ ricardo@pep.ufrj.br
}

Marcos M. Borges, D.Sc.

Faculdade de Engenharia da UFJF

mborges@engprod.ufjf.br

\begin{abstract}
O objetivo deste artigo é discutir as principais questões envolvendo a gestão do conhecimento no processo de desenvolvimento de produtos. A complexidade e a interdisciplinaridade do processo de desenvolvimento de produtos assim como sua característica coletiva e de formulação incompleta são discutidos neste trabalho, de forma a explicitar o ambiente de tomada de decisão de uma equipe de projeto. Os tipos de conhecimento envolvidos no processo de desenvolvimento de produtos são identificados e discutidos de forma a mostrar as dificuldades encontradas pelos projetistas para a criação de um contexto comum de referência. $\mathrm{O}$ artigo também aborda as tecnologias que auxiliam as equipes de desenvolvimento de projeto na sua tarefa, ressaltando as que ajudam a execução de trabalho colaborativo à distância, permitindo a formação de grupos e a cooperação na execução das tarefas remotamente. Alguns exemplos são apresentados e comentadas as possibilidades oferecidas por alguns ambientes, para que pessoas geograficamente distantes mantenham um entendimento compartilhado de um problema, nos quais o conhecimento é adquirido em situações singulares. A noção de contexto na aquisição de conhecimentos de projeto é explorada e é explicado como ambientes virtuais possibilitam aos participantes estruturarem seu conhecimento contextual e compartilharem seu conhecimento prático. O artigo conclui apresentando algumas características de ambientes virtuais de auxílio ao desenvolvimento de produtos e indica algumas possibilidades futuras dessas tecnologias.
\end{abstract}

Palavras-chave: gestão do conhecimento; processo de desenvolvimento de produtos; tecnologias de projeto colaborativo.

This paper discusses the main issues involving knowledge management in the design process. The design process complexity is explored, as well as the collective character of this activity. Some topics involving decision making of illdefined problems are presented in order to explain how decisions are taken in the design activity. The types of knowledge involved in the design progression are identified and the difficulties that arise when doing collective decision making as well. The paper describes web-based technologies that improve teamwork performance, allowing participants to team up and cooperate in projects by interacting remotely in a virtual environment. Some examples are presented showing how information technology permit people geographically apart to maintain a shared conception of a problem, in which knowledge is learned in applied situations. The notion of context in the acquisition of these types of knowledge is explored and it is explained how virtual environments enable participants to structure contextual knowledge and partially share their individual's tacit knowledge. The paper concludes highlighting some features of virtual environments and adressing some issues for future development.

Keywords: Knowledge management; product development ; web-based tecnologies

\section{Introdução}

A grande contribuição da Engenharia de Produção no século XX foi o aumento da produtividade do trabalho manual. Os estudos de Marx, Taylor, Ford, Fayol, Deming, etc. resultaram em novos métodos, novas técnicas e novas formas de organizar o trabalho. Desde Taylor e Fayol, a produtividade do trabalho manual na indústria tem crescido em média $3 \%$ a.a., o que significa 
que ela aumentou cinqüenta vezes desde aquela época.

Taylor advogava que operários não precisavam apresentar habilidades para executar as tarefas, bastando executar os movimentos repetidos previamente planejados pela gerência. Taylor argumentava que o que tornava o trabalho manual mais produtivo era o conhecimento da gerência e a sua habilidade em organizar as tarefas, sincronizar as atividades e fornecer os meios tecnológicos adequados. Na mesma vertente, Ford estabeleceu a linha de montagem na segunda década do século XX e intensificou o trabalho mantendo os princípios de racionalização e padronização já difundidos.

O modelo de administração científica se difundiu pela Europa e pelo Japão ao longo da segunda metade do século XX, assumindo outras denominações com princípios ligeiramente diferentes dos originais. Esse modelo funcionou bem enquanto o cenário mundial da manufatura era constituído de produtos padronizados e com pequena variedade.

Ao final do século XX, a realidade mundial tinha se modificado bastante. Por um lado, as empresas passaram a oferecer produtos diversificados com menor escala produtiva. Nesse sentido, várias mudanças foram feitas tanto ao nível da tecnologia de fabricação quanto nas formas de gestão da produção e do trabalho. Por outro lado, nesse mesmo período, o trabalho ligado a atividades não manufatureiras (serviços) se multiplicou, representando hoje $2 / 5$ da força de trabalho dos Estados Unidos (DRUCKER, 1999).

Esse cenário provocou modificações profundas no modo de produção: as estratégias adotadas pelas empresas centraram-se nas inovações técnicas, organizacionais e mercadológicas, que por sua vez foram beneficiadas pelos avanços verificados, no mesmo período, nas áreas de microeletrônica, informática e comunicações. Em relação aos produtos, as principais estratégias adotadas pelas empresas foram: a redução do tempo de lançamento de novos produtos, a ampliação das opções de produtos customizados e um esforço concentrado na melhoria da qualidade. Forjou-se, portanto, um novo padrão de produção industrial centrado em novas formas de gestão da produção, nas tecnologias de automação, nas tecnologias de informação e nas tecnologias de comunicação.

Essa nova realidade do setor fabril modificou os requisitos exigidos para os trabalhadores. As fábricas passaram a buscar um trabalhador qualificado atualmente segundo grau completo - com capacidade de iniciativa e de coordenação e com condições de manipular informações abstratas, tais como as existentes em um programa de máquina a comando numérico ou num sistema de controle da manufatura. O trabalho fabril passou, portanto, a não poder prescindir das capacidades plenas dos operários para poder produzir uma gama de produtos diferenciados com produtividade. $\mathrm{O}$ novo padrão produtivo modificou a maneira de se fabricar produtos, assim como afetou o modo de se projetar novos produtos. Por outro lado, os produtos se tornaram mais complexos, na medida que cada vez mais incorporam os avanços tecnológicos na sua constituição. Atualmente, a atividade de desenvolvimento de novos produtos está definitivamente vinculada à estratégia de inovação tecnológica traçada em cada organização, sendo mundialmente reconhecida como um fatorchave no bom desempenho empresarial. As empresas têm plena consciência que seu sucesso é fortemente dependente da maneira como projetam seus produtos e de sua habilidade de organizar, processar e aprender através das informações relacionadas ao ciclo de desenvolvimento dos seus produtos.

Além disso, o contexto onde se desenvolve a atividade de projetar produtos se tornou extremamente complexo, envolvendo de um lado um ambiente industrial globalizado onde produtos são projetados simultaneamente em mais de um país, ou projetados em um país e fabricado em um outro; e do outro lado uma quantidade enorme de atividades intensivas em conhecimento embutidas no artefato final. A atividade de projeto passou cada vez mais a incorporar conhecimentos científicos e a utilizar métodos científicos e modelagem matemática na resolução dos problemas que se apresentam ao longo do seu desenvolvimento.

A presença do virtual na sociedade se refletiu diretamente na atividade industrial, onde o aumento crescente da quantidade de trabalho relacionada à informação já suplanta a quantidade de trabalho exercida sobre a matéria propriamente dita (NAVEIRO, 2001). Nesse sentido, à medida que os produtos são mais complexos, mais se gasta em projetar, desenhar, simular, testar, modelar matematicamente, etc. A Boeing envolveu um contingente enorme de pessoas dedicadas a incorporar no projeto do avião modelo 777 os conhecimentos tecnológicos de engenharia da época e ao mesmo tempo, aproveitar os conhecimentos adquiridos na análise dos problemas encontrados no desenvolvimento dos aviões anteriores. Foram 6.800 funcionários da Boeing, associados a mais 10.000 técnicos e engenheiros dos diversos fornecedores, exercendo funções de concepção e validação, envolvendo atividades nas quais o resultado do trabalho pode ser um modelo matemático, a formulação de um novo material mais leve e resistente, um software para atender a uma finalidade específica, etc.

A complexidade de projetar produtos não reside 
somente na complexidade do artefato propriamente dito. Se analisarmos a estrutura organizacional empregada atualmente nas indústrias aeronáutica e automobilística, verificamos que se trata de uma estrutura em rede na qual fornecedores de primeira linha são parceiros da empresa-mãe e parte integrante da equipe de projeto. Os exemplos da Renault no desenvolvimento do modelo Clio II e o da Embraer no desenvolvimento da nova aeronave para 70 passageiros (EMB 170) podem ser citados. Nos dois projetos, as empresasmãe desenvolveram seus novos produtos com um número considerável de parceiros, os quais compartilharam contratualmente os resultados do trabalho conjunto com a empresa-mãe.

Finalizando, podemos dizer que a atividade de projetar artefatos no ambiente industrial atual se desdobra em dois aspectos complementares. De um lado, temos as habilidades dos engenheiros, dentre as quais a capacidade individual de abstração e a capacidade de criação de interfaces com outros universos de especialização têm se mostrado muito mais importantes que a aplicação de fórmulas. Do outro lado, os projetos vêm sendo desenvolvidos em rede, padrão atual de desenvolvimento de produtos nas grandes empresas; o que passa a requerer dos profissionais habilidades de negociar os diversos fatores que condicionam o projeto e de criar um discurso de comunicação capaz de reconciliar os diversos universos de especialização.

A questão que se coloca hoje em dia é a mesma que foi colocada por Taylor no final do século XIX para o trabalho físico: como melhorar a produtividade do trabalho intelectual, como o encontrado, por exemplo, nas atividades de concepção de um novo produto? A atividade de projeto, assim como outras atividades profissionais, é intensiva em conhecimento e normalmente sujeita a restrições muitas vezes conflitantes que precisam ser ultrapassadas, e envolve um processo de negociação para se chegar a um resultado viável.

Neste contexto, o objetivo deste artigo é apresentar alguns experimentos realizados no desenvolvimento de ambientes virtuais de apoio ao projeto, a partir da discussão das questões envolvendo a gestão do conhecimento no processo de desenvolvimento de produtos.

\section{Processo de Desenvolvimento de Produtos (PDP)}

Projetar é uma atividade complexa. Os problemas enfrentados por engenheiros são mal-estruturados e incompletos. O projetar é um processo baseado em conhecimento no qual dados, informação e conhecimento são processados simultaneamente por uma equipe de profissionais envolvidos na definição do ciclo de vida de um produto. O Processo de Desenvolvimento de Produtos (PDP) articula uma série de atividades tais como planejamento do produto, desenvolvimento do produto, síntese do produto e resolução de problemas. Além disso, o projetar envolve um processo incremental de aprendizagem como parte integrante das atividades do projetista. O PDP engloba uma sequiência típica de etapas nas quais o nível de incerteza diminui à medida que o processo evolui; a progressão do projeto pode ser vista como uma coleção de estágios sucessivos nos quais idéias abstratas se transformam em um produto.

O projetar é algo visto com um alto grau de inovação. Entretanto, o que se verifica no interior das empresas é que a prática do projeto se concentra em modificações e melhorias incrementais nos produtos existentes. Alguns projetos têm um alto grau de inovação, mas a maioria segue uma trajetória diferente, onde o grau de inovação não é alto. Nesses casos, a estrutura do artefato não é conhecida e vai emergir a partir da própria atividade de projeto. De uma maneira geral, o PDP é conduzido de forma planejada e organizada, de maneira a manter as atividades de projeto consistentes com os objetivos definidos inicialmente.

Os tipos de projeto usualmente encontrados na indústria são o projeto adaptativo e o projeto variante; ambos envolvendo o uso de estratégias conhecidas, ou partidos consagrados de projeto para chegar a novas soluções. Nesses casos, certas classes de solução e a estratégia de decomposição do problema são conhecidas previamente. Em outras palavras, a percepção inicial da estrutura do produto é conhecida e os conhecimentos necessários para resolver os problemas já estão identificados como, por exemplo, no caso do projeto de casas populares e apartamentos para a classe média. Entretanto, há sempre alguma particularidade nas restrições do projeto, resultando que outros tipos de conhecimento são sempre necessários no projetar.

Projeto e aprendizagem são atividades correlatas, nas quais encontrar um novo conceito envolve a busca e a aquisição de novos conhecimentos. Nos estágios preliminares da progressão do projeto, uma maneira de entender e de estruturar um problema de projeto é a recuperação de casos anteriores para, com isso, formatar um conhecimento abstrato sobre o problema a ser explorado mais adiante, como nas situações de "raciocínio baseado em casos" (TANG, 2001; KOLODNER, 1983). É um processo indutivo de aprendizagem que inclui a assimilação de novos conhecimentos num corpo de conhecimentos organizados para uso futuro. A informação coletada em projetos anteriores é reformatada e reorganizada, possibilitando engenheiros e outros profissionais efetuar generaliza- 
ções, e ao mesmo tempo aproveitar idéias abstratas usadas em situações particulares anteriores para situações análogas que se apresentam.

Projeto e aprendizagem são processos sociais, como descrito na literatura de comunidades virtuais (WENGER, 1998) e em ciência do projeto (NAVEIRO e OLIVEIRA, 2001; BUCCIARELLI, 1994). Nesse sentido, o projetar é considerado muito mais como comunicação e colaboração efetivas, um ambiente de negociação e tomada de decisão no qual os participantes da equipe têm um conhecimento compartilhado que lhes habilita a perceber o que é relevante para ser compartilhado e como apresentar a informação de forma útil à equipe.

Projetar um produto ou uma edificação envolve a percepção da estrutura do artefato, estrutura essa que muda continuamente ao longo da progressão do projeto; assim como o projetar envolve o estabelecimento de estágios ou etapas do projeto, patamares da evolução do projeto que consolidam um corpo de novas idéias geradas ao longo do processo. Os atributos do artefato capturados pelos participantes e seus relacionamentos com o todo permitem a clarificação da organização das tarefas do projeto, de acordo com o estágio em que se encontra o projeto, e em consonância com o universo de especialização de cada membro da equipe.

A forma com a qual os participantes identificam os atributos do artefato é dependente do contexto, uma vez que cada um cria um contexto interpretativo do que é o artefato integrando seu universo de especialização com os objetivos comuns estabelecidos para o projeto. Profissionais atuantes em desenvolvimento de produtos pensam e trabalham de acordo com seu instrumental de normas e procedimentos, instrumental este vinculado à especialização técnica de cada um. Por sua vez, o próprio artefato influencia como os participantes se relacionam e identificam as tarefas a serem cumpridas por cada um.

Por outro lado, o projeto de artefatos pode ser caracterizado como uma atividade cognitiva. Vários pesquisadores do campo de conhecimento da ergonomia cognitiva têm procurado entender a natureza da expertise em projeto para, a partir daí, avaliar a adequação das ferramentas computacionais disponíveis para auxílio ao processo de projeto. Essa abordagem realça as atividades intelectuais de solução de problemas e as estratégias usadas pelos designers para reduzir a complexidade das tarefas de projeto (KARSENTY, 1995). As principais estratégias mentais utilizadas são os mecanismos de associação, decomposição e prototipagem associadas às representações externas do artefato (croquis, diagramas, etc.).
Essas duas abordagens de entendimento da natureza do projetar - coletiva e individual - são complementares. O processo de projeto de um produto é normalmente conduzido por uma equipe multidisciplinar, com cada especialista sendo responsável por uma parte do projeto e, ao mesmo tempo, sendo obrigado a negociar com os demais especialistas os requisitos e restrições comuns de forma a alcançar uma solução factível. Esses dois aspectos da atividade de projeto devem ser considerados ao selecionar ferramentas computacionais de auxílio ao projeto (NAVEIRO, 1997).

No passado, o papel representado pelo computador no desenvolvimento de um projeto se limitava a cálculos, desenhos e análises. Todas essas atividades são feitas após o designer já ter tomado todas as decisões principais. No início, os sistemas de projeto assistido por computador (CAD) eram usados apenas para a elaboração de desenhos, porém, sua evolução recente mostra que o CAD atualmente segue a tendência de incorporar cada vez mais conhecimento nas suas novas versões.

Os sistemas CAD atuais são baseados em características (feature-based) e incorporam conhecimentos em domínios específicos, permitindo que se possa fazer a avaliação dos conceitos simultaneamente ao projetar, isto é, um engenheiro ao projetar um mecanismo pode verificar a interferência entre duas peças simplesmente simulando seu movimento. A avaliação da manufaturabilidade de um produto é uma tarefa incorporada às funções de uma série de sistemas CAD comerciais e pode ser customizada facilmente para se adaptar às práticas correntes de uma determinada empresa. Uma nova geração de sistemas CAD pode incorporar as práticas correntes de uma empresa na avaliação da viabilidade de novos conceitos de projeto. Esses novos sistemas incorporam conhecimento recuperado de projetos anteriores disponibilizando o conhecimento relevante para os designers. Situação semelhante a esta é relatada por Zacklad (2001) ao explicar o processo de capitalização de conhecimentos no seio das empresas.

Com a incorporação cada vez maior de conhecimentos específicos às plataformas $\mathrm{CAD}$, começaram a surgir os sistemas denominados de KAD (Knowledge Aided Design), como por exemplo, os que incorporam conhecimentos relativos ao processo de fabricação dos componentes projetados, ou seja, tais sistemas simulam e projetam não só o produto final, mas também o processo de fabricação do mesmo, orientando os projetistas a fazerem modificações em seu projeto para melhorar a sua manufaturabilidade. Apresentamos na Figura 1 um exemplo do sistema Mold Flow utilizado para o projeto e simulação de produção de peças plásticas. 


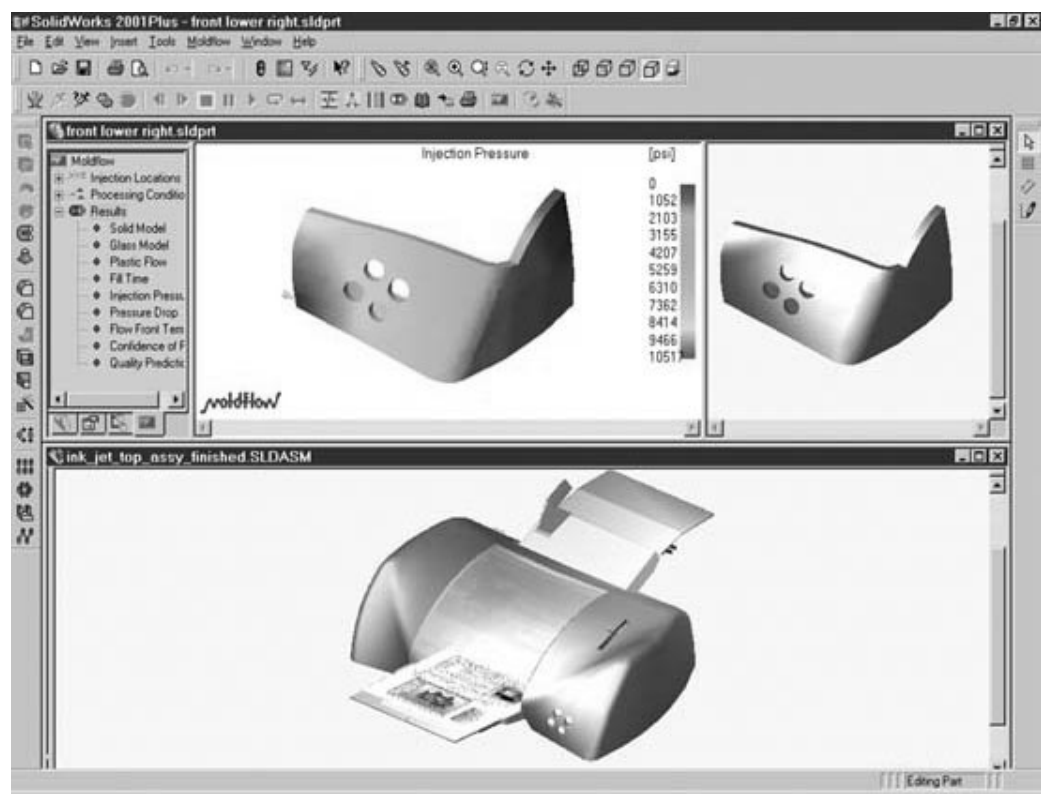

Figura 1 - Tela do Mold Flow

Outra gama de programas são os destinados à simulação visual e realidade virtual. Neste grupo se enquadram os programas para "renderização", iluminação e visualização de elementos com acabamento fotorealístico, além dos sistemas mais atuais de realidade virtual. Através deles, os conceitos podem ser visualizados na tela do computador com todo o realismo que terão depois de prontos. Sistemas de realidade virtual são utilizados para análise do comportamento dos produtos em condições de uso e possibilitam o contato com o usuário antes mesmo da confecção de um protótipo. Na construção civil, por exemplo, a realidade virtual possibilita o passeio virtual dentro da edificação para se ter uma noção de organização e espaço do empreendimento.

Nos últimos anos, bastante esforço foi colocado no desenvolvimento de sistemas computacionais para auxílio ao trabalho em grupo, e em particular, ao trabalho de equipes de projeto. As empresas estão cada vez mais internacionalizadas, com filiais em todas as partes do mundo e os produtos estão sendo projetados em parceria entre as empresas e seus fornecedores mundiais. Uma série de colaborações "um a um" ocorre quando se desenvolve o projeto de um produto e as empresas precisam coordenar e tornar compatível a troca de dados, informações e conhecimentos entre diferentes contextos. Além disso, existem barreiras geográficas a ultrapassar com o auxílio dessas ferramentas informatizadas. No entanto, a maioria dos sistemas desenvolvidos para auxiliar a atividade de projeto é de uso individual.

\section{Projeto e conhecimento}

Projetar é uma atividade impulsionada por conhecimento na qual requisitos e restrições são transformados na descrição de um produto. O processo de projeto envolve uma grande quantidade de conhecimentos acumulados por engenheiros e técnicos durante sua vida profissional. As fontes de conhecimento são as mais diversas, variando de educação formal a experiência individual, incluindo o conhecimento adquirido em casos semelhantes à situação corrente. A definição de uma estrutura cognitiva para os problemas de projeto é processo intensivo em conhecimento que envolve tanto conhecimentos práticos como teóricos.

\subsection{Tipos de conhecimento}

A definição de conhecimento pode ser construída a partir da conceituação de dados e de informações. Dados são símbolos percebidos por um indivíduo e transformados em informação pela interpretação do que é percebido. Nesse sentido, informação é um conjunto de dados com significado. Logo, informação é um conjunto estruturado de dados com conteúdo semântico expresso em linguagem natural. É, portanto, um conjunto de dados com significado visível, i.e., algo compreensível e passível de ser compartilhado entre indivíduos.

Engenheiros e técnicos usam basicamente dois tipos de conhecimento quando criando novos produtos: conhecimento processual e conhecimento declarativo. 
O primeiro é um conhecimento expresso por procedimentos enquanto o segundo se refere a conhecimentos expressos em equações, relações lógicas ou agentes em programas de computador. Isto nos leva à distinção entre teoria e prática ou "conhecer como" (know how) ou "conhecer que" (know that). A teoria se refere a modelos, princípios ou regras usados para explicar certos fenômenos e tipo de conhecimentos normalmente adquiridos através da educação formal. Os conhecimentos práticos se referem a algo que pode ser aprendido de pessoas executando eficientemente uma tarefa.

A noção de conhecimento prático possibilita uma outra abordagem dessa questão. Certos tipos de conhecimento necessitam de prática para serem apreendidos, enquanto outros tipos de conhecimento não apresentam esta característica. $\mathrm{O}$ conhecimento explícito ou o conhecimento declarativo podem ser compartilhados no seio de uma equipe sem dificuldades, enquanto o conhecimento tácito é implícito e pessoal. Certos conhecimentos tácitos que não são explicitáveis podem, no entanto, ser compartilhados através da prática (VIGOTSKY, 1978). Esse é o caso de várias habilidades manuais e também se aplica a situações de concepção de produtos nas quais o conhecimento de projeto não pode ser assimilado sem a devida prática.

Essas distinções são muito importantes para os ambientes coletivos de projeto nos quais a aquisição de conhecimentos e a validação de conhecimentos são questões centrais no seio de uma equipe, dentro da qual o conhecimento tácito individual precisa ser compartilhado e transformado em algo compreensível pelos participantes. Esses movimentos entre conhecimento tácito e explícito são bem conhecidos (NONAKA e TAKEUCHI, 1995), porém Pomerol e Brezillon (2001) trouxeram novas contribuições com a introdução da noção de contexto em processos de tomada de decisão.

Contexto é um tópico importante a ser levado em conta quando se investiga processos de tomada de decisão e processos de aprendizagem. Do ponto de vista do desenvolvimento de projeto de produtos, o contexto pode ser visto como uma coleção de condições relevantes relacionadas a uma vizinhança que torna única e compreensível a situação investigada. Uma pessoa realizando uma tarefa normalmente identifica em seu repertório de conhecimentos qual é o relevante para a execução da tarefa. Essa porção de conhecimentos julgados importantes para uma determinada tarefa é denominada de conhecimento contextual.

De acordo com Pomerol e Brezillon (2001), dentro de uma determinada atividade de tomada de decisão em um projeto, uma porção do conhecimento contextual é recuperada, estruturada e adaptada conforme a situação concreta em foco, reduzindo, dessa forma, o universo de busca. $\mathrm{O}$ resultado desse processo é denominado contexto processual e é associado a uma determinada etapa do processo decisório. No caso do projetar, a reutilização de conhecimentos abstraídos de projetos anteriores envolve a construção de um contexto interpretativo das situações anteriores para torná-las úteis para a tarefa corrente.

Outro aspecto do conhecimento processual é um tipo de instanciação. Isso significa que o conhecimento contextual necessita de uma maior especificidade para ajustar-se à situação em tela. Isso ocorre quando, por exemplo, engenheiros e arquitetos representam graficamente suas concepções. O fenômeno ocorre na esfera individual do projetista e a representação gráfica expressa o conhecimento processual representado numa folha de papel ou numa tela de computador.

A relação entre essa argumentação e as situações de projeto é muito próxima. Quando se atribui uma tarefa de projeto para um membro menos experiente de uma equipe, sua percepção do conhecimento contextual não é imediata, i.e., recuperar o conhecimento relevante do seu repertório não é fácil para um novato. $\mathrm{O}$ conhecimento de projeto é construído de forma incremental baseado na experiência prática. A habilidade de tratar situações novas é derivada de experiências prévias, como em um processo indutivo de aprendizagem. As técnicas indutivas de inferência, i.e, abstração, especialização, simplificação e compressão são particularmente relevantes para a aquisição de conhecimentos (TANG, 2001).

A diferença entre especialistas e novatos é que os especialistas são mais conscientes do seu conhecimento. A memória de um especialista tem um componente contextual que inclui a experiência; fatos são armazenados de modo semântico, no qual são definidos pelo papel que cumprem nas diferentes situações. O processo decisório de especialistas é baseado em casos ao invés de regras, sendo mais automático e mais rápido. Essa discussão sobre novatos e especialistas é similar à anterior sobre contexto. $\mathrm{O}$ contexto processual pode ser visto como uma reorganização da memória na qual os fatos são re-arrumados de acordo com as situações.

Por outro lado, as tarefas de projeto são normalmente mal definidas e incompletas. Dessa forma, para completar os requisitos implícitos nas tarefas, um novato precisa de ajuda para tornar explícito o conhecimento contextual associado à situação proposta. A falta de informação presente em todos os projetos de engenharia é completada por interações pessoais estabelecidas entre os profissionais da equipe de projeto. Isso reforça 
a necessidade de auxiliar os membros da equipe em seus processos argumentativos e em seus processos de tomada de decisão.

Diferentes tipos de linguagem são utilizados nos processos de tomada de decisão em projetos. Cada componente do produto em desenvolvimento pode ser descrito de maneira diferenciada, conforme a necessidade do momento. Pode-se enumerar quatro tipos de linguagem usadas para representar um artefato (ULLMAN, 1992):

- Semântica: usada na representação textual ou verbal de um artefato, dando-lhe um nome reconhecido pelos demais participantes;

- Gráfica: usada na representação gráfica do artefato através de um desenho técnico (linguagem gráfica codificada) ou através de diagramas ou croquis tridimensionais;

- Analítica: usada na descrição das funções do artefato, seja através de equações, funções matemáticas ou regras;

- Física: usada na representação do artefato através de modelos físicos ou maquetes.

Essas categorias são bastante úteis no momento da estruturação de bases de conhecimento para apoio ao desenvolvimento de produtos. Os recursos atuais da tecnologia de informação permitem usar modelos tridimensionais do artefato como base geométrica comum para a integração de pontos de vista de uma equipe de projeto a respeito de um determinado artefato.

\section{Cooperação e CSCW}

O termo Computer Supported Cooperative Work (CSCW) foi cunhado no final da década de 80 englobando uma larga variedade de aplicações direcionadas para o trabalho em equipe. O termo trabalho colaborativo tem sido usado para designar diversas situações de trabalho em que se verifica o envolvimento de pessoas trabalhando em conjunto, de forma planejada e em tarefas interconectadas.

Argumenta-se que, em teoria, todo trabalho coletivo é essencialmente cooperativo ou colaborativo, mas há consenso que trabalho colaborativo é um tipo de trabalho que envolve um conjunto de atividades relativamente autônomas e não hierarquicamente coordenadas, caracterizando-se pelo compartilhamento de responsabilidades. Também se refere a um arranjo de pessoas engajadas no desempenho de tarefas, através de um processo direto de comunicação, vinculado à produção de um produto ou serviço.
Em contraste com os vínculos espontâneos de processos produtivos interconectados, o trabalho cooperativo na atividade de projeto é caracterizado por ser planejado e com interações pré-definidas (BANNON e SCHMIDT, 1991). Em uma equipe de projeto, os participantes estão cientes da metodologia de projeto e dos objetivos a serem alcançados, o que define o compromisso de certas tarefas genéricas na resolução de problemas. As tarefas de um projeto são vinculadas a determinados procedimentos, que são geralmente usados pelos engenheiros de forma mais ou menos padrão na construção de estratégias de solução adequadas às especificidades de uma dada situação. Neste sentido, existem algumas atividades coletivas em uma equipe de projeto que se repetem, adaptandose a cada caso ou a cada etapa da progressão do projeto, não importando a natureza ou o tipo do produto em desenvolvimento.

O trabalho colaborativo compreende interações simbólicas diretas e indiretas, além de formas coletivas e distribuídas de interação. As tarefas podem ser conduzidas de uma maneira distribuída por profissionais semi-autônomos que planejam suas próprias estratégias e mudam seu comportamento de acordo com as circunstâncias. Essa situação coincide com o caso de uma equipe de projeto, na qual os participantes têm as suas áreas de especialização próprias, porém interconectadas pelas restrições do projeto e pelos seus objetivos.

O CSCW tanto pode ser considerado como uma disciplina técnica que se dedica ao desenvolvimento e construção de sistemas informatizados para grupos e organizações, quanto uma ciência social que pretende entender as bases sociais para a construção desses sistemas (ACKERMAN, 2000). Esta argumentação se baseia no fato de haver um vazio sócio-técnico no CSCW, ou seja, um desencontro entre o que é requerido pelas comunidades virtuais e o que é possível de ser desenvolvido com as tecnologias atuais. Ackerman (2000) e outros autores ressaltam que a tecnologia disponível atualmente e os sistemas em uso não são capazes de capturar as nuances e sutilezas verificadas nos processos de comunicação presenciais.

Conseqüentemente, estes sistemas assumem um entendimento compartilhado da informação, ou seja, a informação é interpretada da mesma forma pelos participantes da equipe. Entretanto, esta compreensão compartilhada (uniforme) normalmente não se verifica em equipes cujos participantes possuem diferentes formações ou são provenientes de outras organizações. Sem o compartilhamento de histórias e significados, ou seja, sem que os membros da equipe tenham formações e experiências semelhantes, os significados têm que ser negociados e a informação acaba perdendo o seu contexto quando se ultrapassam as fronteiras das áreas 
de conhecimento de cada membro da equipe. São essas as principais dificuldades para a sincronização cognitiva dos membros de uma equipe de projeto e para a construção de um contexto interpretativo comum.

Uma equipe de projeto é um grupo de especialistas em vários assuntos cooperando num objetivo comum que precisa de algumas facilidades para melhorar a eficiência do seu trabalho. O espaço de trabalho (o local das atividades coletivas) é muito mais um ambiente de negociação de restrições e de tomada de decisões, no qual a identificação das tarefas e as relações entre elas permitem identificar as áreas de conhecimento e o papel a ser cumprido por cada participante.

Dessa forma, considerando o foco nas características de ambientes virtuais na gestão do processo de desenvolvimento de produtos, verifica-se que este tipo de cooperação envolve diversos processos, tais como a comunicação, a negociação, a coordenação, a corealização e o compartilhamento, entre outros. Portanto, para que pessoas em um mesmo local ou geograficamente distribuídas trabalhem cooperativamente, faz-se necessário um ambiente de apoio aos processos de comunicação entre as mesmas.

O ambiente computacional que implementa os processos de apoio à cooperação, e assim possibilita o trabalho, a produção em conjunto e a troca de informações, denomina-se groupware ou sistema de trabalho cooperativo apoiado por computador. Numa visão ainda mais prática considera-se que groupware é qualquer ferramenta que ajude as pessoas a trabalharem em conjunto, mais fácil e eficazmente.

Atualmente, o principal alvo dos fornecedores de software é o desenvolvimento de soluções para o desenvolvimento de projetos à distância. As soluções disponíveis no mercado estão centradas na incorporação de ferramentas cooperativas no fluxo de trabalho de projeto e estão restritas a um determinado campo de conhecimento. A seguir, apresentamos uma tela (Figura 2) da solução proposta pela Autodesk para projetos no setor de A/E/C (arquitetura, engenharia e construção).

\section{Requisitos funcionais de um sistema colaborativo para o desenvolvimento de produtos}

A estruturação e o desenvolvimento de ambientes para o trabalho cooperativo leva em conta diversos aspectos, desde a definição da funcionalidade até os aspectos relacionados à interface com os usuários. No que se refere à funcionalidade, pode-se considerar os aspectos que se seguem como os mais relevantes (GANESHAN et al., 2001):

- A linguagem e o meio utilizado para descrever as informações;

- As formas de comunicação utilizadas, ou seja, síncronas ou assíncronas;

- O tipo de arranjo da base de dados: distribuída, central ou compartilhada.

A interface desses ambientes deve permitir a identificação da presença de um usuário no sistema, bem como mostrar o que está sendo realizado pelos demais colaboradores que participam da equipe, como por exemplo, a utilização de múltiplas janelas para mostrar as atividades de cada usuário, ou ainda, o uso de cores

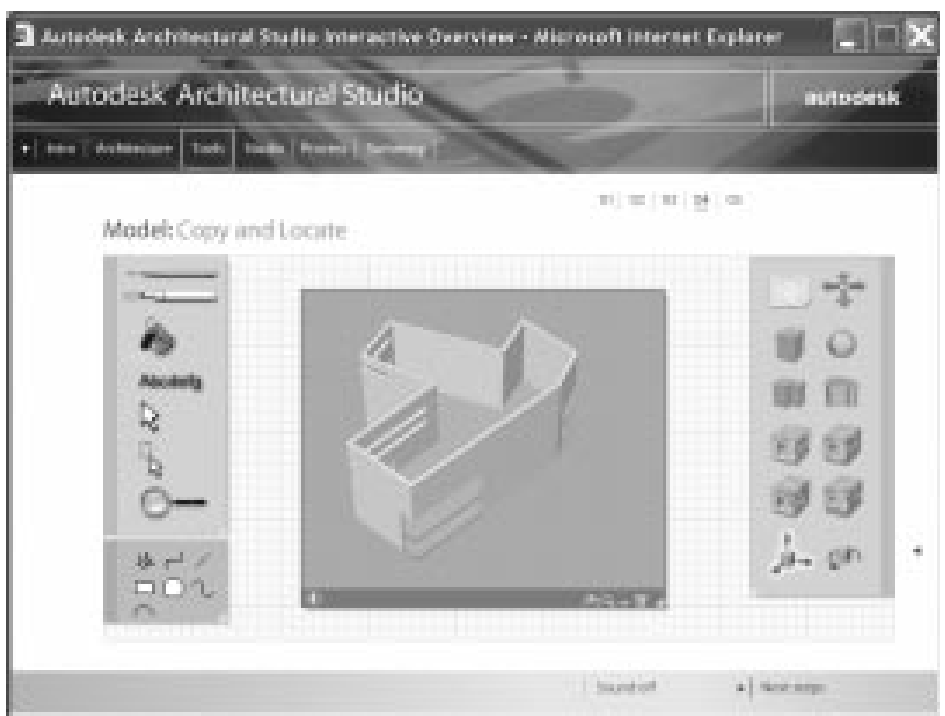

Figura 2 - Tela do Architectural Studio 
diferentes para identificar o que foi feito por cada usuário. Entretanto, o que se tem observado é que tradicionalmente, as interfaces desses sistemas têm sido desenvolvidas tendo em mente apenas um usuário.

Existem diferentes maneiras de uma equipe de trabalho interagir. Os membros da equipe podem optar por se conectar ao sistema ao mesmo tempo (trabalho síncrono), ou podem trabalhar numa mesma tarefa em tempos diferentes (trabalho assíncrono). Pode-se considerar as seguintes formas de trabalho cooperativo:

- Encontros presenciais que ocorrem em um local e ao mesmo tempo;

- Encontros assíncronos que ocorrem em um mesmo local, porém em tempos diferentes;

- Encontros síncronos distribuídos que ocorrem ao mesmo tempo, porém em locais diferentes;

- Encontros totalmente distribuídos que ocorrem em locais diferentes em diferentes momentos.

A Figura 3 mostra as várias possibilidades nas quais um grupo pode trabalhar, dependendo da sua distribuição geográfica e temporal.

A possibilidade da cooperação sem restrições de tempo e espaço tem sido considerada a forte motivação para a criação e uso de sistemas cooperativos. Existem outras motivações e facilitadores que podem ser considerados no desenvolvimento do trabalho cooperativo, conforme os tópicos descritos a seguir:

- Nos sistemas CSCW, pessoas mais tímidas possuem uma maior oportunidade de se expressarem, pelo fato de o ambiente computacional ser impessoal e menos ameaçador para os já habituados a esse ambiente;

- Todas as contribuições podem ser armazenadas no sistema para uma futura análise dos participantes, facilitando o acompanhamento e o andamento do trabalho pelos coordenadores das sessões e/ou participantes;

- As contribuições são mais tangíveis e documentáveis. Os participantes são bastante motivados a contribuir, obtendo a sensação de realização e posse, mesmo em relação aos documentos escritos por outros participantes.

Nos sistemas CSCW assíncronos, pessoas mais agressivas têm menor chance de obter o domínio das discussões. Todos têm chances iguais de participação, sem que a exposição de suas contribuições seja interrompida indevidamente.

De maneira geral, um ambiente de projeto colaborativo envolve ferramentas para a comunicação, ferramentas para a visualização de desenhos e ferramentas para o gerenciamento e controle do andamento do projeto. De forma resumida, as principais funcionalidades de um sistema colaborativo são as seguintes:

- Bancos de dados inter-relacionados;

- Sistemas de busca genéricos e por categoria;

- Sistema de cadastro de dados;

- Ferramentas de comunicação assíncrona, tais como fóruns de discussão;

- Ferramentas de comunicação síncrona, tais como as salas de discussão;

- Recursos de visualização de desenhos vetoriais;

- Recursos de visualização de imagens estáticas com alguma interatividade;

- Recursos de gerenciamento da documentação do projeto.

Levantamentos realizados por Soares (2001) encontraram alguns sistemas colaborativos comerciais de auxílio ao projeto. O quadro da Figura 4 apresenta as principais características dos sistemas comerciais disponíveis no mercado nessa época.

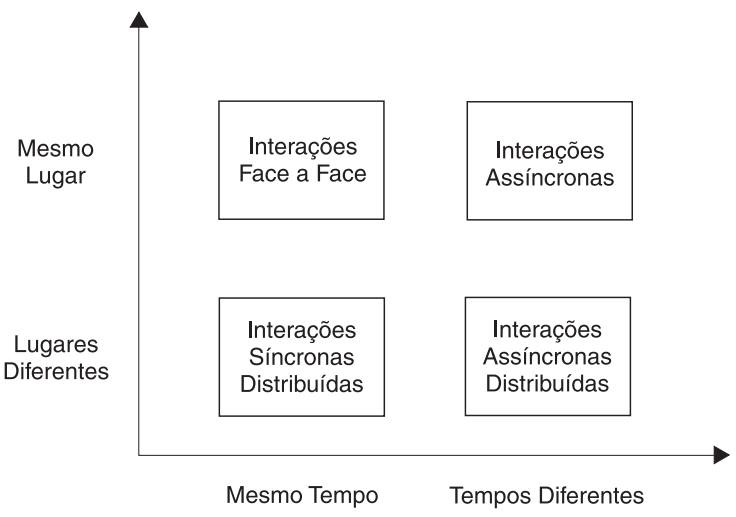

Figura 3 - Distribuição Geográfica x Temporal 


\begin{tabular}{|c|c|c|c|c|c|c|c|}
\hline & Project Quest & PROLOG & ProjectNET & SAD/Sistrut & ProSys & Team Builder & Primavera \\
\hline $\begin{array}{c}\text { Principal } \\
\text { Característica }\end{array}$ & $\begin{array}{l}\text { Gerenciador } \\
\text { de } \\
\text { Documentos }\end{array}$ & $\begin{array}{l}\text { Gerenc. de } \\
\text { Documentos } \\
\text { c/ Workflow }\end{array}$ & $\begin{array}{l}\text { Gerenc. de } \\
\text { Documentos } \\
\text { c/ Workflow }\end{array}$ & $\begin{array}{l}\text { Gerenciador } \\
\text { de } \\
\text { Documentos }\end{array}$ & $\begin{array}{l}\text { Gerenciador } \\
\text { de } \\
\text { Documentos }\end{array}$ & $\begin{array}{l}\text { Gerenc. de } \\
\text { Documentos } \\
\text { c/ Workflow }\end{array}$ & $\begin{array}{l}\text { Custos e } \\
\text { Gerenc. de } \\
\text { Processos }\end{array}$ \\
\hline $\begin{array}{l}\text { Visualizar } \\
\text { Documentos }\end{array}$ & Sim & Sim & Sim & Sim & Sim & Sim & Sim \\
\hline $\begin{array}{l}\text { Recursos de } \\
\text { Workflow }\end{array}$ & Não & Sim & Sim & Não & ÑÑ- & Sim & $\tilde{N} \tilde{N}-$ \\
\hline $\begin{array}{c}\text { Comunicação } \\
\text { Assíncrona }\end{array}$ & Sim & Sim & Sim & Não & $\tilde{N} \tilde{N}-$ & Sim & $\tilde{N} \tilde{N}-$ \\
\hline $\begin{array}{l}\text { Comunicação } \\
\text { Síncrona }\end{array}$ & Sim & $\begin{array}{l}\text { Messages, } \\
\text { Chat e } \\
\text { Whiteboard }\end{array}$ & $\begin{array}{l}\text { Messages, } \\
\text { Chat e } \\
\text { Whiteboard }\end{array}$ & $\begin{array}{c}\text { Vídeo } \\
\text { Conferência }\end{array}$ & Sim & Sim & ÑÑ- \\
\hline $\begin{array}{l}\text { Registro das } \\
\text { Comunicações }\end{array}$ & $\tilde{N} \tilde{N}-$ & Sim & Sim & Não & Sim & $\tilde{N} \tilde{N}-$ & $\tilde{N} \tilde{N}-$ \\
\hline $\begin{array}{l}\text { Relatórios e } \\
\text { Formulários }\end{array}$ & Sim & Sim & Sim & Não & Sim & Sim & Sim \\
\hline $\begin{array}{l}\text { Agenda e } \\
\text { Reuniões }\end{array}$ & Sim & Sim & Sim & Não & Sim & Sim & $\tilde{N} \tilde{N}-$ \\
\hline Interface & Boa & Boa & Muito Boa & Ruim & Boa & Boa & Boa \\
\hline Tecnologia & ASP & ÑÑ- & ÑÑ- & ASP & Domino & $\tilde{N} \tilde{N}-$ & ÑÑ- \\
\hline
\end{tabular}

Figura 4 - Principais características dos sistemas cadastrativos comerciais de auxílio ao projeto

\section{0 desenvolvimento de ambientes colaborativos para o desenvolvimento de produtos}

Geralmente, os ambientes comerciais utilizam tecnologia proprietária, porém, várias pesquisas e desenvolvimentos de ambientes vêm sendo feitas no âmbito acadêmico, todas elas utilizando código aberto. Normalmente, são utilizados servidores web do tipo Apache e servidores de banco de dados do tipo MySql. O conteúdo dos ambientes é escrito em linguagem HTML e a

implementação das diversas funcionalidades é feita em script PHP.

A Figura 5 mostra a estrutura básica de um sistema cliente $\mathrm{x}$ servidor utilizado para a implementação desses ambientes, bem como de seus recursos de visualização em páginas web.

Além dessas linguagens e tecnologias para edição dinâmica de páginas web, existem outras tecnologias específicas para visualização de conteúdos gráficos, tanto para exibição de imagens estáticas do tipo mapa de bits como exibição de modelos tridimensionais.
Dentre essas tecnologias, destaca-se a Viewpoint Experience Technology (VET), que permite a geração de arquivos gráficos tridimensionais para publicação na web a partir de modelos digitais elaborados em diversos programas comerciais com modeladores 3D.

A título de exemplo, mostramos em seguida na Figura 6 a arquitetura básica de um ambiente colaborativo para apoio ao desenvolvimento de projetos de produtos. Trata-se de um sistema baseado em conhecimento para auxílio a projetos de produtos de base mecânica composto de três módulos. O primeiro módulo é uma base de dados, onde conhecimentos formalizados sobre materiais, componentes mecânicos, mecanismos, etc. são cadastrados e indexados para busca futura. Esta base de dados é construída obedecendo-se às categorias de linguagem propostas anteriormente por Ullman (1992).

As bases de dados são interconectadas e indexadas de forma a permitir o acesso mais rápido ao conhecimento ou às informações requeridas através do uso de um sistema de busca categorizado, i.e., a busca pode ser realizada somente dentro de um sub-módulo (por exemplo, em mecanismos). Os conteúdos relacionados 


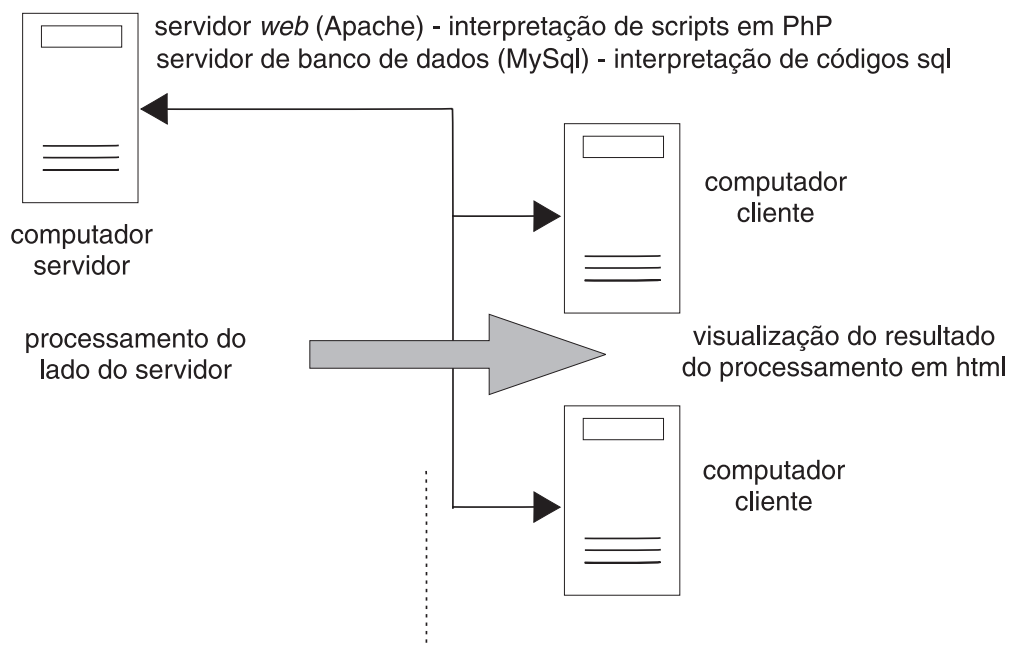

Figura 5 - Fluxograma esquemático de uma plataforma cliente x servidor

à pesquisa podem ser indexados em outros submódulos como, por exemplo, em mecanismos ou materiais relacionados a um determinado elemento pesquisado.

Outras categorias de informação e conhecimentos podem ser acrescentadas, de forma que o ambiente possa ser ampliado conforme as necessidades dos usuários, ou quando novas categorias de conhecimento relevantes para as tarefas de projeto em questão são identificadas.

Os conhecimentos vinculados a representações gráficas também podem ser incluídos nas bases de dados. As representações em duas dimensões normalmente são imagens vetoriais compactadas, podendo ser visualizadas diretamente no browser através do uso de plug-ins específicos. Essas visualizações podem ser consideradas como a tradução compacta de desenhos vetoriais complexos produzidos nas plataformas $\mathrm{CAD}$; podendo ser impressos e receber comentários e revisões no próprio desenho exibido pelo plug-in.

A visualização em três dimensões de conteúdos gráficos estende ainda mais a capacidade de representação do conhecimento de projeto em ambientes colaborativos via $w e b$. Tais recursos se baseiam em scripts de compactação e, atualmente, é possível a representação de conteúdos razoavelmente complexos sem grandes perdas no desempenho e na velocidade de atualização de imagens em uma conexão padrão com a Internet. Os recursos mais avançados deste tipo de

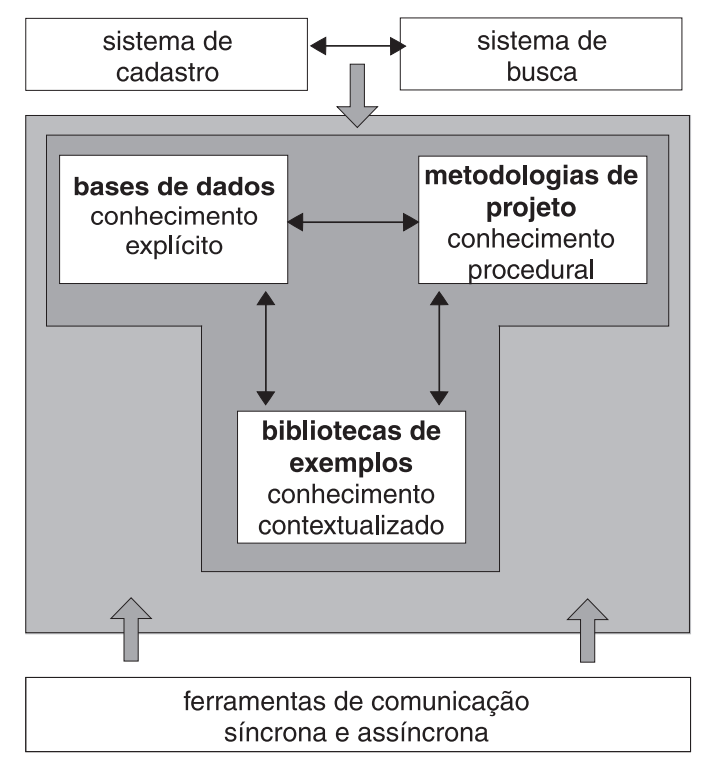

Figura 6 - Arquitetura básica de um ambiente virtual para desenvolvimento de produtos 


\section{Produto \& Produção, vol. 8, n. 3, p. 91-106, out. 2005}

tecnologia permitem a associação de descrição textual ou imagens estáticas a áreas determinadas do objeto tridimensional de forma semelhante aos recursos de mapeamento de imagens raster, bem como animações construídas em modeladores gráficos tridimensionais de uso corrente.

A associação destes tipos de representações gráficas com os recursos de comunicação síncrona e assíncrona proporcionados pelos ambientes virtuais permite transpor o divórcio entre as argumentações semânticas e verbais de projeto com a sua visualização, o que normalmente se verifica em ambientes digitais.

Conhecimentos descritos analiticamente podem ser armazenados na base de dados através de recursos de programação do tipo scripts de linguagem Javascript, entre outros. Estes recursos permitem a incorporação de funcionalidades dinâmicas inseridas na interface de uma página web para, por exemplo, cálculos de tensões máximas admissíveis a partir de dados obtidos em tabelas.
O segundo módulo incorpora conhecimentos processuais, i.e., conhecimentos relacionados às metodologias de projeto, as quais indicam as principais etapas de desenvolvimento de um projeto de produto e os principais métodos utilizados em cada uma delas.

O terceiro e último módulo é constituído por bibliotecas de exemplos e estudos de caso que se articulam com as metodologias apresentadas no segundo módulo. Estas bibliotecas cumprem a função de repositórios de conhecimentos explícitos associados a um contexto específico (conhecimento contextualizado) e que podem ser recuperados para uso em novos projetos similares aos descritos na biblioteca. A estrutura de representação deve ser feita por meio de tipologias de produto e indexada de forma a facilitar o acesso de informação através de um sistema de busca categorizada. Dessa forma, o conhecimento gerado em projetos anteriores pode ser reformatado e reorganizado, permitindo que engenheiros e projetistas possam generalizar idéias e conceitos que são explícitos em situações particulares, de maneira a poderem fazer uso destas informações em situações análogas.

\section{SisPro Components}

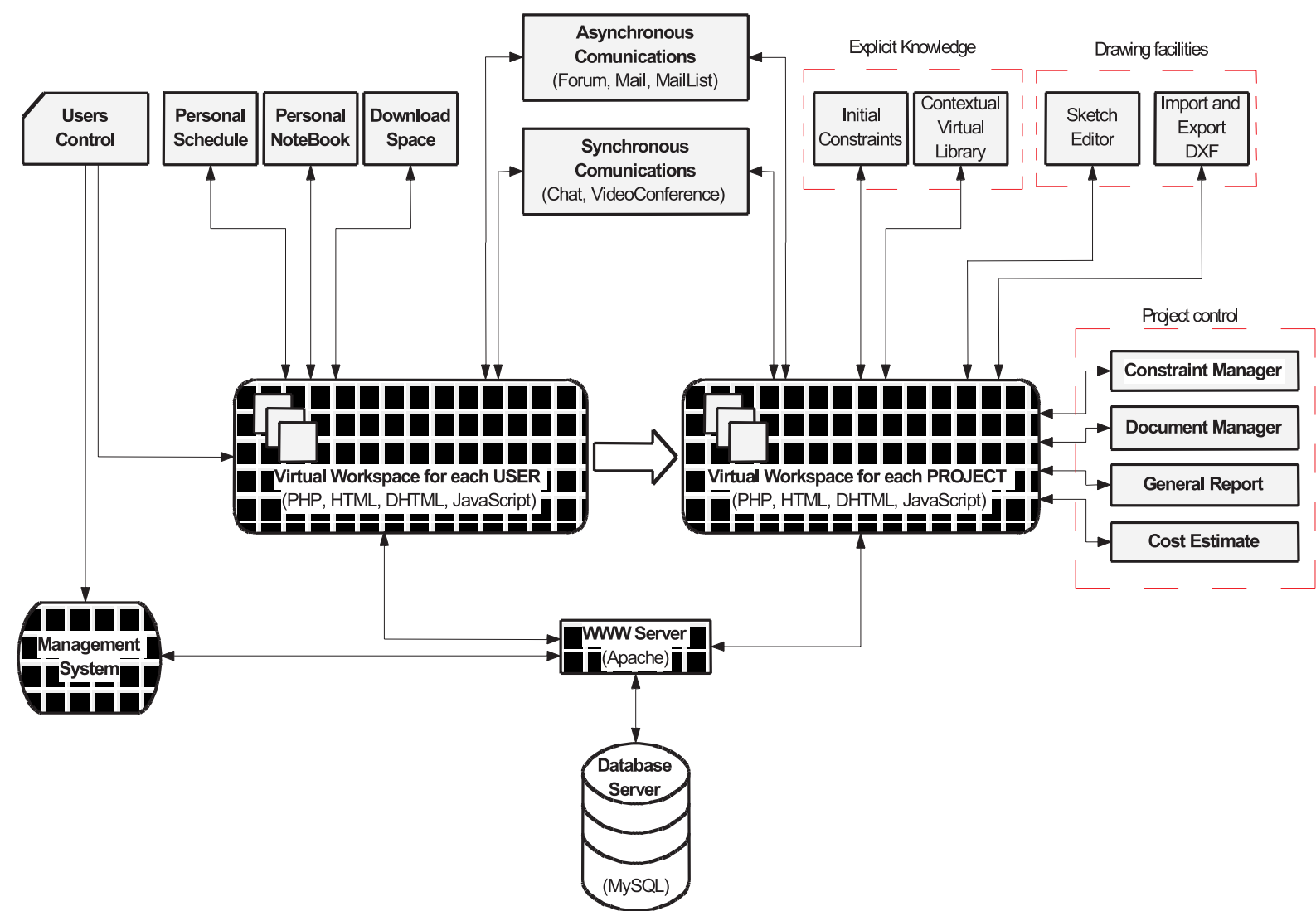

Figura 7 - Arquitetura do ambiente SisPro 
Além das bases de dados inter-relacionadas e acessadas através do sistema de buscas, a arquitetura do ambiente tem a capacidade de oferecer recursos de comunicação síncrona e assíncrona que desempenham um papel duplo. Em primeiro lugar, permitem um processo de argumentação e tomada de decisão com a possibilidade de rastreamento das argumentações. Além disso, esses recursos também possibilitam a construção de conhecimentos explícitos, i.e., argumentações ou questões postadas em um fórum de discussões viabilizam a explicitação de conhecimentos do tipo tácito ou de práticas processuais que traduzem a experiência dos membros de uma equipe de projeto.

Apresentamos a seguir um exemplo de ambiente para projeto colaborativo, resultado do trabalho de um aluno de doutorado do Programa de Engenharia de Produção da COPPE/UFRJ, e que se encontra atualmente em fase de testes de usabilidade. $\mathrm{O}$ ambiente denomina-se SisPro (www.sispro.ufjf.br) e é vinculado a aplicações do setor de A/E/C. A Figura 7 apresenta a arquitetura do ambiente SisPro.

O ambiente SisPro compreende um conjunto de funcionalidades que viabilizam comunicação síncrona e assíncrona e interação entre os membros de uma equipe de projeto. Existe um espaço virtual de trabalho para cada usuário que permite sua interação com os demais participantes que estão on-line, assim como um espaço virtual para cada projeto, o que possibilita comunicação e interação controlada dentro da equipe do projeto em tela (BORGES et al., 1999).

O ambiente tem dois objetivos principais: integrar o conhecimento relevante para o projeto de uma edificação e desenvolver habilidades de equipe entre os participantes. Os pressupostos do desenvolvimento do ambiente SisPro foram os de auxiliar os membros da equipe a estruturar o conhecimento contextual, permitir o compartilhamento do conhecimento tácito de cada um e promover a aquisição de novos conhecimentos através de interações objetivas entre os membros da equipe.

O ambiente SisPro preenche os seguintes requisitos:

- Permite que cada participante crie, visualize e modifique documentos associados a um projeto. Essa funcionalidade é sujeita a restrições dependendo dos direitos atribuídos a cada participante;

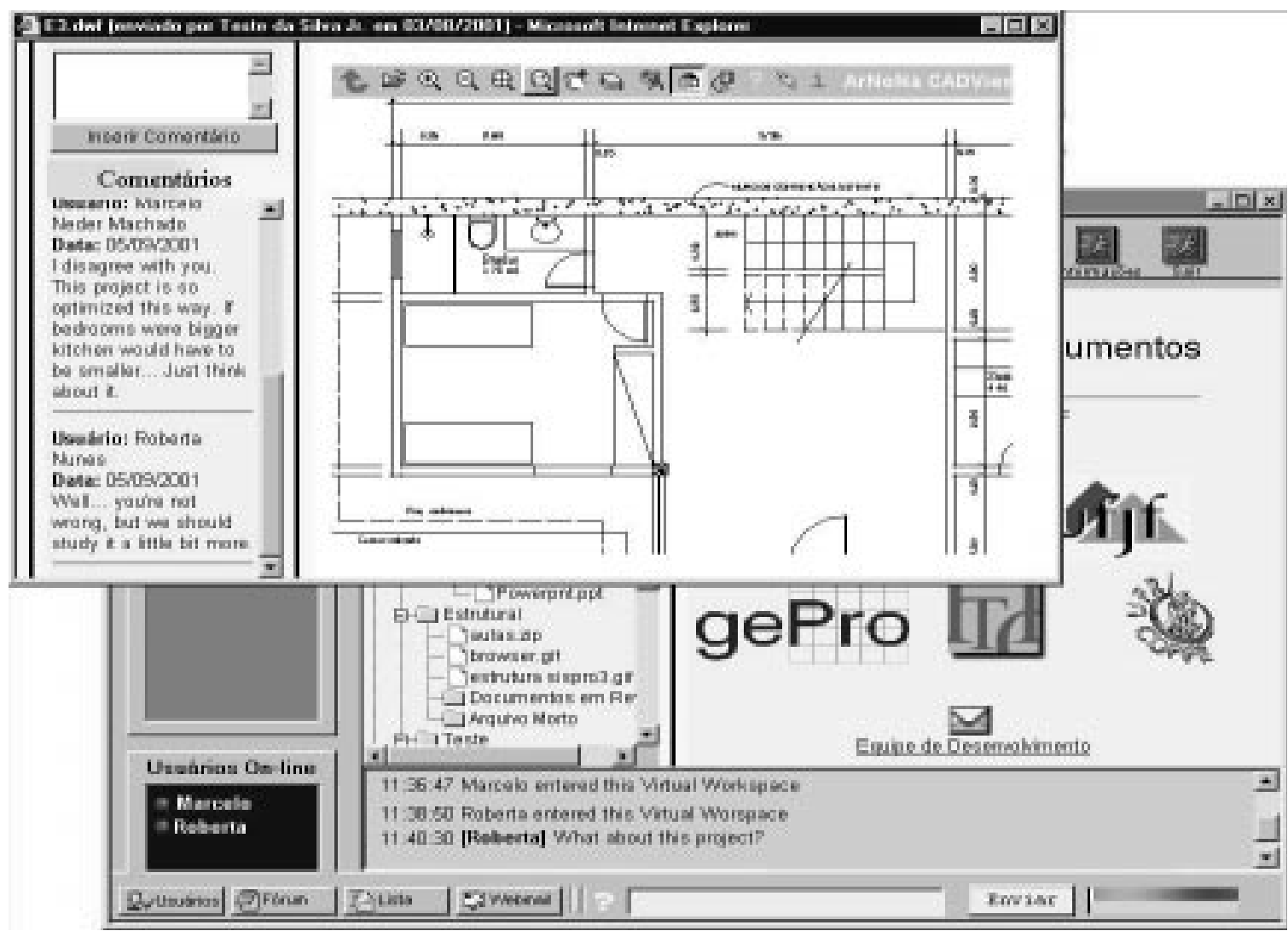

Figura 8 - Tela do SisPro com a argumentação calcada no conceito visualizado 


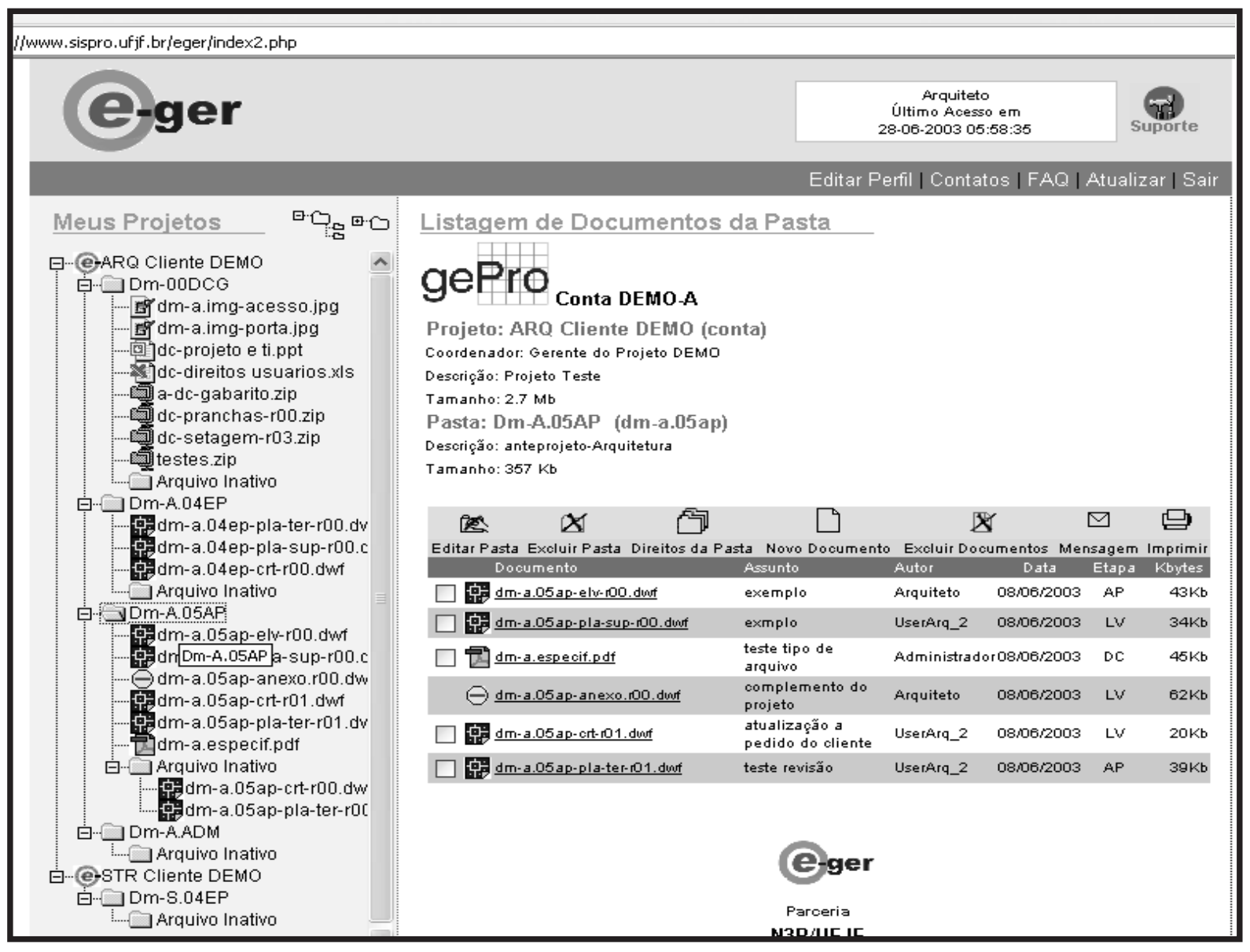

Figura 9 - Tela com as opções do menu de entrada do sistema e-Ger

- Permite que cada participante fique ciente das modificações feitas nos documentos de acordo com as suas áreas de interesse e com o seu papel dentro da equipe do projeto;

- Permite argumentação assíncrona e possibilita compartilhar informação visual e textual. Informação visual pode ser integrada a uma argumentação textual;

- Permite discussão síncrona;

- Permite a identificação e a estruturação do conhecimento contextual.

Processos de aprendizado e de aquisição de conhecimentos ocorrem através das interações estabelecidas no seio da equipe. $\mathrm{O}$ fórum estruturado fornecido pelo ambiente permite a estruturação dos problemas do projeto, a manutenção da consistência do processo de tomada de decisão e permite o rastreamento das decisões tomadas. O raciocínio diagramático viabilizado pelo ambiente SisPro permite que a argumentação textual esteja integrada com as representações gráficas evitando o aparecimento do divórcio contextual (GIBOIN, 1999). Há evidências de uma quebra no processo de comunicação caso a argumentação não esteja integrada com a representação gráfica respectiva. O exemplo mostrado na Figura 8 apresenta a funcionalidade do SisPro para vincular uma discussão entre arquiteto e cliente sobre uma planta baixa de uma casa. Além disso, o desenho mostra quem são os intervenientes na discussão, identificando de quem é a argumentação postada.

Além disso, o ambiente SisPro viabiliza um editor gráfico para a etapa de anteprojeto com funcionalidade de avaliação aproximada de custos dos conceitos gerados. O controle e a edição de documentação do projeto são feitos por um módulo ("Gerenciador de Documentos") denominado e-Ger, que permite ter o rastreamento completo da progressão do projeto do ponto de vista documental. O módulo e-Ger conta com recursos que visam organizar, gerenciar, cadastrar, visualizar e permitir a atualização e a modificação dos documentos associados ao projeto. Permite também comunicar somente aos envolvidos na elaboração um determinado documento sobre qualquer alteração ou atualização do mesmo. Além disso, o e-Ger funciona como repositório único de informações de um ou mais 
projetos armazenando e disponibilizando de forma organizada documentos para visualização, download ou impressão. A Figura 9 mostra uma tela do e-Ger com as opções oferecidas pelo menu de entrada no sistema.

\section{Comentários finais e conclusões}

A introdução de ambientes cooperativos baseados na web representa uma inovação tecnológica na prática profissional de engenheiros e arquitetos. Empresas distribuídas mundialmente, projetos sendo compartilhados entre a matriz e seus fornecedores de primeira linha estão associados à melhoria da eficiência das ferramentas Internet e a custos decrescentes de conexão reforçam a oportunidade de se explorar as possibilidades da Internet em situações de projeto e de capacitação profissional.

Projetar e aprender são processos coletivos nos quais a interação que emerge entre os participantes promove o aprendizado. Os processos de aprendizagem englobam um conjunto de atividades intelectuais relacionadas à resolução de problemas e processos de negociação entre os participantes. Decisões individuais necessitam ser validadas e integradas com as restrições coletivas que mudam dinamicamente à medida que o projeto progride. O processo de projeto é também recursivo: é necessário manter o histórico de tomada de decisões, de forma a se poder retornar e procurar novos caminhos de solução sem perder o rumo. Essa é uma das características do SisPro, uma vez que ele permite gravar o processo de argumentação e as hipóteses consideradas na tomada de uma decisão.

Buscar informação e aprender são partes integrantes do processo de projeto, assim como encontrar novas soluções envolve a busca e aquisição de novos conhecimentos. Os ambientes virtuais descritos nesse artigo disponibilizam bibliotecas nas quais o conhecimento contextual pode ser recuperado para em seguida ser utilizado na situação em tela.

Há consenso entre as empresas que o uso de ambientes colaborativos no desenvolvimento de projetos traz uma melhor organização aos diversos documentos gerados ao longo do projetar, sendo muito mais eficiente que o uso do correio eletrônico para gerenciar e controlar as versões dos documentos. Todavia, seu uso ainda é muito incipiente e no caso do setor de $\mathrm{A} / \mathrm{E} / \mathrm{C}$ somente encontrado em empresas que estão envolvidas em projetos com parceiros internacionais.

O trabalho colaborativo auxiliado por computador para desenvolvimento de projetos ainda está nos estágios iniciais de seu desenvolvimento. As possibilidades abertas pelas novas tecnologias vão viabilizar aos profissionais de projeto reproduzir virtualmente o conceito de atelier de projeto, espaço no qual os membros de uma equipe de projeto compartilham seu conhecimento numa situação singular. Sistemas robustos e integrados às ferramentas comerciais de uso corrente ainda não estão disponíveis, confirmando que esta área ainda precisa avançar bastante, bem como criar seus próprios padrões de interconectividade.

\section{Referências}

ACKERMAN, M. The Intellectual Challenge of CSCW: The gap between social requirements and technical feasibility. Human-Computer Interaction, vol.15, p.179203., 2000.

BORGES, M.; NAVEIRO, R.; SOUZA FILLHO, R. SISPRO - A Computer Support System for conceptual design in architecture. Proceedings of the $12^{\text {th }}$ International Conference in Engineering Design. Munich, Heurista aug, 1999.

BANNON, L. ; SCHMIDT, K. CSCW: Four Characters in Search for a Context. Studies in Supported Cooperative Work. Bowers J. \& Benford S. (editors), Elsevier, p. 3-16, 1991.

BRÉZILLON, P.; POMEROL, J. - Ch. About some relationships between knowledge and context. Proceedings of the $3^{\text {rd }}$ International Conference on Modeling and Using Context, Dundee, p. 461-464, july 2001 .

BUCCIARELLI, L. Designing Engineers. Cambridge, The MIT Press, 1994.

DRUCKER, P. ASAP: Peter Drucker - The Next Information Revolution. Disponível em www.versaggi.net. Visitado em 09/04/2001.

GANESHAN, R.; GROBLER, F.; WANG, C. and COIMBATORE, V. CITYWORK: Application of Collaborative Technologies for Infrastructure Management. Journal of Computing in Civil Engineering, vol.15 n.1, p. 74-80, 2001.

GIBOIN, A. Contextual Divorces: Towards a framework for identifying critical context issues in collaborativeargumentation system design, Modeling and Using Context, Trento, Berlin, Springer, p. 471-474, sept. 1999.

KARSENTY,L.; BRÉZILLON, P. Cooperative problem solving and explanation. Expert Systems with Applications, vol.8 n.4. p. 445-462, 1995.

KOLODNER, J. Towards an understanding of the role of experience in the evolution from novice to expert. International Journal of Man-Machine Studies, vol.19, p. 497-518, 1983. 
108 Produto \& Produção, vol. 8, n. 3, p. 91-106, out. 2005

NAVEIRO, R. The role of computer support for integrated product design. Proceedings of the XI International Conference on Engineering Design, Tampere, A. Riitahuhta, p. 465-468, 1997.

NAVEIRO, R.; BRÉZILLON, P. ; BORGES M. Learning in Context: Contextual Libraries in Architecture Distance Education. Anais do XII Simpósio Brasileiro de Informática na Educação, Vitória, nov. 2001.

NAVEIRO, R. ; OLIVEIRA, V. O projeto de engenharia, arquitetura e desenho industrial. Juiz de Fora: Editora da Universidade Federal de Juiz de Fora, 2001.

NONAKA, I. ; TAKEUCHI, H. The knowledge-creating company. New York: Oxford University Press, 1995.
TANG, M. Inductive learning techniques in design process: a design concept learning system. Integrated Computer-Aided Engineering, vol.8, p. 171-186, 2001.

ULLMAN, D. The Mechanical Design Process. New York: Mac-Graw Hill, 1992.

VIGOTSKY, L. Mind in Society: The Development of Higher Psychological Processes. Cambridge: Harvard University Press, 1978.

WENGER, E. Communities of practice. New York: Cambridge University Press, 1998.

ZACKLAD, M. ; GRUNDSTEIN, M. Management des Connaissances: Modèles d'entreprise et applications. Paris: Hermes, 2001. 



\section{Produto \& Produção}

\section{Política editorial e normas para publica- ção de artigos}

Publicação quadrimestral (tiragem em fevereiro, junho, outubro) do Programa de Pós Graduação em Engenharia de Produção da Escola de Engenharia da Universidade Federal do Rio Grande do Sul.

\section{Política Editorial}

São aceitos artigos de interesse da Engenharia de Producão, nas áreas de Gerência de Produção, Qualidade, Gestão Econômica, Ergonomia e Segurança do Trabalho, Engenharia do Produto, Pesquisa Operacional, Estratégia e Organizações, Gestão da Tecnologia, Sistemas de Informação e Conhecimento, Gestão Ambiental e Ensino de EP. Os trabalhos devem ser originais ou divulgados previamente de forma restrita, contendo contribuições para o avanço científico, tecnológico, institucional e de ensino, tanto a nível teórico (revisão de literatura, "estado da arte", etc) quanto prático (resultados de pesquisa, relatos de trabalhos de aplicação prática, etc).

Obs: Por artigo divulgado de forma restrita entendese aquele divulgado em:

a) anais de congresso estrangeiro;

b) anais de congresso nacional mas apenas em forma resumida;

c) revista estrangeira de pouca penetração nacional. Os artigos serão submetidos a 3 membros do Conselho Científico da revista para avaliação. Os originais enviados, aprovados ou não aprovados, não serão devolvidos.

Normas para publicação, formato e padronização

\section{Envio do arquivo}

Enviar arquivo editado em Word for Windows para o endereço de e-mail da revista: pep@ufrgs.br ou pelo site www.ufrgs.br/pep

\section{Idioma}

O artigo pode ser em português, espanhol ou inglês.

Os artigos em português e espanhol devem conter um abstract em inglês, além do resumo.

Artigos em inglês devem conter resumo em português além do abstract.

\section{Formatação:}

Margens: 2,5 cm, letra: Times corpo 11; espaço entre linhas: simples. O artigo deve ter no máximo 20 laudas.

$\mathrm{O}$ arquivo deve apresentar, na $1 \stackrel{\text { a }}{\text { página: título do }}$ artigo, nome(s) do(s) autor(es), titulação mais elevada, instituição de origem, resumo de no máximo 150 palavras e $\mathbf{3}$ palavras-chave, abstract em inglês de no máximo 150 palavras e 3 keywords.

As palavras estrangeiras devem aparecer no texto $\mathrm{em}$ itálico (ex: buffer).

Em números decimais, usar vírgula $(2,5)$ ao invés de ponto (2.5).

As figuras devem ser de boa qualidade, inseridas no texto. As figuras serão impressas em preto e branco e tons de cinza. As legendas, abaixo das figuras, devem iniciar com a palavra Figura, o número respectivo em algarismo arábico

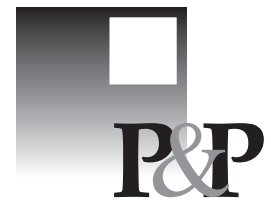

(as figuras são numeradas consecutivamente) e um traço (ex: Figura 1 - Diagrama de...)

As tabelas devem ser de boa qualidade, inseridas no texto. Devem ter legenda no topo, iniciando com a palavra Tabela, o número respectivo em algarismo arábico (as tabelas são numeradas consecutivamente) e um traço (ex: Tabela 1 - Distribuição de...)

Os gráficos devem ser feitos em preto e branco e tons de cinza.

O rodapé deve ser utilizado apenas para a colocação das referências dos apuds.

Junto com o artigo, deve ser enviado um arquivo com o nome de cada um dos autores e seu endereço para contato (correio normal + e-mail + telefone).

O conteúdo dos artigos, bem como a sua forma, é de inteira responsabilidade dos autores.

A bibliografia consultada ou citada deve estar de acordo com os modelos a seguir:

Artigo de anais

WILLMORE, L. Determinants of market structure: a brazilian case study. In: ENCONTRO BRASILEIRO DE ECONOMETRIA, 8., Brasília, 1986. Anais... Rio de Janeiro: Sociedade Brasileira de Econometria, $1986 \mathrm{v}$. 2, p. 12-18.

Citação em livro

CARVALHO, R. de Q. Capacitação tecnológica, revalorização do trabalho e educação. In: FERRETI, Celso João et al. (org.) Novas tecnologias, trabalho e educação: um debate multidisciplinar. Petrópolis: Vozes, 1994. p.15-22.

\section{Livro}

CHIAVENATO, I. Introdução a Teoria Geral da Administração. 4. ed. São Paulo: Makron Books, 1993. 243p.

\section{Artigo de periódico}

DIAMOND, W. J. Three dimensional models of extreme vertices designs for four component mixtures. Technometrics, v.9, n.3, p. 8-15, Aug. 1967.

\section{Enviar os artigos para:}

\section{Revista Produto \& Produção}

site: www.ufrgs.br/pep e-mail: pep@ufrgs.br

\section{Maiores informações: \\ Universidade Federal do Rio Grande do Sul - E. E. Programa de Pós-Graduação em Engenharia de Produção Praça Árgentina, $n^{\circ} 9,2^{\circ}$ andar, sala LOPP CEP 90040-020 / Porto Alegre - RS}

tel: (51) 3316-3948

fax: (51) 3316-4007

Contato: Cristine Brondani Suporte técnico - Revista Produto\&Produção 